\title{
Correlation between Dental Environment and Perceived Stress Scale among Dental Students during the COVID-19 Pandemic in Indonesia
}

\author{
Tri Erri Astoeti ${ }^{1 *}$, Howis Josephine ${ }^{2}$, Armelia Sari Widyarman ${ }^{3}$, Widijanto Sudhana ${ }^{1}$
}

\begin{abstract}
1Department of Preventive and Public Health, Faculty of Dentistry, Trisakti University, West Jakarta, Indonesia, ${ }^{2}$ Undergraduate Student, Faculty of Dentistry, Trisakti University, West Jakarta, Indonesia, ${ }^{3}$ Department of Oral Biology, Faculty of Dentistry, Trisakti University, West Jakarta, Indonesia
\end{abstract}

\begin{abstract}
Academic stressors in a medical educational environment are related to two factors. This study was carried out in order to analyze the correlation between the dental environment and perceived stress among dental students during the COVID-19 pandemic. The respondents were 422 undergraduate dental students and the validated Modified Dental Environmental Stress (DES) and Perceived Stress Scale (PSS) questionnaires were used. Furthermore, the Spearman correlation analysis was used to measure the correlation between DES and PSS score. The result showed that five dental stressors were noted to have the strongest correlations with PSS ( $p$-value >0.40). They include expectation towards dental school ( $p$-value $=0.431$ ), lack of confidence to be a successful dentist ( $p$-value $=0.424)$, lack of confidence to become a successful dental student ( $p$-value $=0.408)$, dental school regulations $(p$-value $=0.401)$ and criticism of school work ( $p$-value $=0.400$ ). In addition, all six DES categories showed a positive correlation with the PSS. Therefore, the dental students collectively displayed moderate perceived stress scores. The overall discoveries from this study showed a positive correlation between the DES and PSS among dental students during the COVID-19 pandemic.
\end{abstract}

Keywords: dental environment, dental student, perceived stress scale

\section{Introduction}

The data on October 21, 2020 obtained by the Indonesia Medical Council stated that there are only 35,863 dentists in Indonesia. However, this number still remains low and is yet to meet the needs of the Indonesian population. ${ }^{1}$ Perceived stress among dental students has become an obstacle towards increasing graduation productivity, especially during the pandemic. ${ }^{2}$ This implies that the coronavirus disease 2019 (COVID19) pandemic has an impact on dental education. ${ }^{3}$

A pandemic is defined as an "epidemic that occurs worldwide or in a very wide region, crossing international borders and typically affecting a large number of individuals". ${ }^{4}$ The outbreak that occurred in Wuhan, China, in December 2019, is a newly discovered infectious disease caused by a beta coronavirus called severe acute respiratory syndrome coronavirus 2 (SARS-CoV-2), which was later officially known as the COVID-19.5 The World Health Organization (WHO) stated that the COVID-19 outbreak is a global health emergency on January 30, 2020 , and finally declared it as a global pandemic on March 11, 2020, due to its rapid and uncontrollable

Correspondence*: Tri Erri Astoeti, Department of Dental Public Health and Preventive Dentistry, Faculty of Dentistry, Trisakti University, Kyai Tapa Street No. 260, Grogol, West Jakarta, Jakarta 11440, Indonesia, E-mail: erriastoeti@trisakti.ac.id, Phone: +62811957969 transmission. ${ }^{6}$ As of October 2020, WHO reported more than 1 million death cases linked to COVID-19 infection worldwide. ${ }^{7}$

Since the beginning of this pandemic, WHO has been publicly recommending several measures to control the spread of SARS-CoV-2 infection. They include the avoidance of crowds and poorly ventilated areas, good hygiene practices such as hand washing and wearing face masks, as well as practicing social distancing. ${ }^{8}$ Although, these measures were initially aimed at reducing the global mortality rate, they have somehow significantly altered the world's orders in many aspects, including daily routine, economy, the stock market and even the world's educational system. ${ }^{8}$ Consequently, many nations have implemented lockdown (general constraints on the population, including instructions to stay at home and work/learn from home) and this has impacted the lives of employees and students across the globe, ranging from elementary to college students, due to the closedown of public places including offices, companies and educational institutions. ${ }^{7,9}$ In the world of dentistry, both in terms of dental practice and education, like other educational majors,

Received : January 11, 2021

Accepted : March 10, 2021

Published: August 24, 2021 
faced challenges in implementing the new procedures, to protect the health of students and dental faculty staffs, while ensuring the continuity of the quality of dental education. ${ }^{10}$ Furthermore, the prevalence of stress and anxiety, especially among dental students, increased with the closure of universities and enforcement of social distancing regulations during this pandemic. ${ }^{11}$

Academic stressors in a medical educational environment are related to several factors, such as large number of difficult materials and the ability of comprehensive examinations to be mastered by students that require a lot of time to study, leaving them with little time to release accumulated stress and anxiety. ${ }^{2}$ The health profession has higher stress levels compared to other field of study. It has been observed that $56.4 \%$ of health professions have high-stress levels and only $20.6 \%$ of nonhealth-related professions have high-stress levels. ${ }^{12}$

Meanwhile, dental students are more likely to experience high-stress levels compared to other health fields. A study found that dental students have higher stress levels compared to other medical students in academic performance with average scores of 2.56 and 2.37, respectively ( $\mathrm{p}$-value $<0.1$ ), clinical responsibility towards patients with average scores of 2.39 and 2.21 (p-value $<0.1$ ), and faculty relationship with average scores of 2.38 and 1.87 , respectively. ${ }^{13}$ Furthermore, based on a study by Al-Sowygh, et al., ${ }^{14}$ the mean and median score of the Perceived Stress Scale (PSS) among dental students is 22.82 and 23, respectively. This study was performed in Saudi Arabia and stated that dental students in the fourth academic year had the highest stress levels (23.97). Meanwhile, they had the lowest stress levels (22.35) in the third academic year. ${ }^{14}$

The dentistry curriculum requires students to have theoretical knowledge and clinical skills simultaneously. In the preclinical period, they are expected to acknowledge theoretical materials in a short time and be introduced to complex dental equipment. Furthermore, during clinical practice, they are required to perform irreversible procedures on frightened patients. These experiences are new and were never carried out during the pre-clinic study period. ${ }^{15-17}$

Therefore, this academic demand requires dental students to be competitive and encourages them to study hard in order to obtain a good education. However, for some students, this stressor causes high-stress levels. ${ }^{18}$ One of the undesirable effects of stress on dental students is intellectual dysfunction and failure to learn. They become ineffective in fulfilling the requirements in the dentistry curriculum due to high-stress levels, with or without physical symptoms. The stress levels also put them in conflicting situations where they have to choose between spending time studying, relaxing, or doing other things outside the scope of dentistry. ${ }^{19}$
A study stated that identifying the stress-causing factors and the levels of stress among dental students may be of assistance in building a strategy to reduce stress levels. ${ }^{20}$ Appropriate strategies contribute to increasing the number of graduates and quality of dental education. This solution is expected to address the ratio of dentists to the population in some countries. Consequently, the stress-causing factors and stress levels among dental students need to be studied in order to formulate an appropriate strategy. ${ }^{21}$ A study of stress levels among dental students at the Faculty of Dentistry Trisakti University has never been carried out. Therefore, this study aims to acknowledge the relation of the stress-causing factors and perceived stress among dental students at the Faculty of Dentistry Trisakti University, primarily during the COVID-19 pandemic.

\section{Method}

This study was based on analytic observation, using cross-sectional study methods. The subjects were undergraduate students at the Faculty of Dentistry Trisakti University, representing the class of 2017-2019. Using the random sampling method, the minimal sample was calculated and the minimal size obtained was $212(\mathrm{~N}=$ 1,500). The respondents were 422 undergraduate dental students. This study was approved by the Ethics Commission of Faculty of Dentistry Trisakti University with approval number 267/S1/KEPK/FKG/2/2020. Furthermore, all questionnaires were developed and confirmed after expert review.

The data used was collected from completed questionnaires. The questionnaires were divided into the Perceived Stress Scale (PSS) and Modified Dental Environment Stress (DES) questionnaire. Perceived Stress Scale questionnaire measured the perceived stress level of the student using Likert scale from 0-4 as follows: 0: never, 1: almost never, 2: sometimes, 3: almost often, 4: often. Subsequently, total scores were calculated by changing the scores for questions number $4,5,6,7$ and 8 into $0=4,1=3,2=3,3=1,4=0$. The total score of the PSS questionnaire analysis was divided into three scales, namely low-stress level (0-13), middle-stress level (14-26) and high-stress level (27-40).14,22

Meanwhile, Dental Environment Stress was measured by events, experiences or stimuli originating from the environments that are able to cause stress. This study modified the DES questionnaires with excluding patient care category. The questions were divided into six categories, namely: self-efficacy, lecturers, workload, clinical training, academic performance pressure and personal/others and scaled with Likert from 1-5 as follows: 1: no stress, 2: less stressful, 3: simply stressful, 4: very stressful, 5: not applicable. ${ }^{14,23}$ Data from the DES questionnaire was categorized with a calculated mean and standard de- 
viation.

The validity of the DES and PSS questionnaires was tested, but due to the modification of questionnaires in this study, the validity was re-tested. The modified DES questionnaires consisted of 29 questions which had an $r$ count more than $r$ table (0.428-0.800). Meanwhile, the PSS questionnaires consisted of 10 questions which had an $r$ count more than $r$ table (0.420-0.867). Therefore, all the questions from both questionnaires were valid.

Reliability tests for both questionnaires were carried out using the Chronbach coefficient alpha, which was also used to determine the reliability of the measuring instrument. According to Bernstein, the minimum coefficient for measuring an instrument is 0.7 and is said to be reliable. ${ }^{24}$ The result of the reliability test for both questionnaires are shown in Table 1. It was concluded that questionnaires are usable since both the DES and PSS were classified as having very high and high reliability respectively.

Data between genders were compared using an Independent Sample T-test. Furthermore, Spearman correlation analysis was used to measure the correlation between the DES and PSS score. Data analysis was carried out using IBM SPSS Statistic Version 24 (IBM Corp., New York, USA).

\section{Results}

A total of 422 responses were recorded in Table 2, among which $87.7 \%$ were female and $12.3 \%$ were male. Furthermore, the mean PSS score for the study population was $20.5( \pm 5.644)$ with a range of 5-38. The male students showed a mean PSS score of $19.3( \pm 5.090)$, while that of the female students was $20.6( \pm 5.712)$. From all the DES factors in Table 3, five factors with the highest mean were selected (Table 4). The factor with the highest mean among the stress-causing factors was 'Fear of failing a module,' which was included in the 'Academic performing pressure category. The DES factor

Table 1. Chronbach Coefficient Alpha of Dental Environment Stress and Perceived Stress Scale Questionnaires

\begin{tabular}{lc}
\hline Questionnaire & Cronbach Coefficient $\alpha$ \\
\hline Dental environment stress & 0.957 \\
Perceived stress scale & 0.773 \\
\hline
\end{tabular}

Table 2. Comparison of Mean Scores, Data Range and Perceived Stress Scale Score between Gender

\begin{tabular}{lrrcl}
\hline Participant & n (\%) & Mean (SD) & Data Range & PSS Category \\
\hline All & 422 & $20.5(5.644)$ & $5-38$ & Moderate stress \\
Male & $52(12.3 \%)$ & $19.3(5.090)$ & $6-38$ & Moderate stress \\
Female & $370(87.7 \%)$ & $20.6(5.712)$ & $5-38$ & Moderate stress
\end{tabular}

Notes: PSS: Perceived Stress Scale, SD: Standard Deviation categories of 'academic performance pressure', 'workload' and 'clinical training', predominated with the mean score of each category being 2.86, 2.69 and 2.85 respectively. The result of the Spearman correlation test indicated that there was a positive correlation between all DES factors and PSS scores (p-value <0.01) (Table 5). Among all DES items, the 5-items with the strongest positive correlations ( $\mathrm{p}$-value $>0.4$ ) were noted in Table 6 .

\section{Discussion}

During the COVID-19 pandemic, many faculties all over the world, including dentistry greatly transformed the traditional face-to-face form of the educational system into online learning in order to pass the educational substances between tutors and students. Despite the adoption of new approaches that are capable of suppressing the spread of COVID-19, the uncertainty about how and when the pandemic will end could significantly im-

Table 3. Dental Environment Stress Factors

\begin{tabular}{|c|c|c|}
\hline Variable & Mean & SD \\
\hline Self-efficacy & 2.53 & 0.763 \\
\hline Lack of confidence to be a successful dental student & 2.60 & 0.891 \\
\hline Lack of confidence to be a successful dentist & 2.71 & 0.918 \\
\hline Insecure feeling towards the future & 2.91 & 0.906 \\
\hline Consider changing to another major & 1.76 & 0.930 \\
\hline Lecturers & 2.03 & 0.714 \\
\hline Faculty environment & 2.11 & 0.940 \\
\hline Number of dishonest faculty in dentistry & 2.27 & 1.027 \\
\hline Rules and regulations for faculty of dentistry & 2.12 & 0.930 \\
\hline $\begin{array}{l}\text { Respondent expectation towards faculty of dentistry vs. } \\
\text { reality }\end{array}$ & 2.28 & 0.913 \\
\hline Lack of input in decision making by faculty of dentistry & 2.140 & 0.950 \\
\hline Gestures of faculty of dentistry towards female students & 1.531 & 0.860 \\
\hline Race discrimination, class status and ethnic group & 1.581 & 0.875 \\
\hline $\begin{array}{l}\text { Inconsistency of feedback on respondent work by } \\
\text { different lecturers }\end{array}$ & 2.100 & 0.965 \\
\hline Workload & 2.69 & 0.834 \\
\hline Number of assignments & 2.50 & 0.926 \\
\hline Less time for relaxation & 2.97 & 0.925 \\
\hline Less time to carry out assignments & 2.58 & 0.950 \\
\hline Clinical training & 2.85 & 0.857 \\
\hline Difficulty in studying clinical procedure & 2.94 & 0.981 \\
\hline Difficulty in learning the skills needed in pre-clinic and & & \\
\hline lab work (skills lab) & 2.74 & 0.911 \\
\hline Academic performance pressure & 2.86 & 0.720 \\
\hline Difficulties in assignments & 2.52 & 0.926 \\
\hline Competition among academic peers & 2.46 & 1.019 \\
\hline Examinations and grades & 3.17 & 0.849 \\
\hline Fear of failing a module & 3.31 & 0.823 \\
\hline Requirements for graduation (Bachelor's degree) & 2.88 & 0.958 \\
\hline $\begin{array}{l}\text { Fear of not being able to catch up if sitting at the back } \\
\text { of the class }\end{array}$ & 2.47 & 0.997 \\
\hline Criticism of the work & 3.03 & 0.720 \\
\hline Personal/Others & 1.91 & 0.760 \\
\hline Financial issue & 2.53 & 1.068 \\
\hline Forced postponement of marriage/engagement & 1.43 & 0.842 \\
\hline Personal physical health & 1.96 & 0.944 \\
\hline Away from home/homesick & 1.78 & 0.983 \\
\hline $\begin{array}{l}\text { Problems with family/spouse regarding the choice to } \\
\text { become a dentist }\end{array}$ & 1.45 & 0.856 \\
\hline
\end{tabular}

Note: SD: Standard Deviation 
Table 4. The Stress-Causing Factor with the Highest Means in Dentistry

\begin{tabular}{|c|c|c|c|}
\hline DES Factor & Category & Mean & SD \\
\hline Fear of failing a module & Academic performance pressure & 3.31 & 0.825 \\
\hline Examinations and grades & Academic performance pressure & 3.17 & 0.850 \\
\hline $\begin{array}{l}\text { Fear of not being able to } \\
\text { catch up if sitting at the } \\
\text { back of the class }\end{array}$ & Academic performance pressure & 3.03 & 0.936 \\
\hline Less time for relaxation & Workload & 2.97 & 0.925 \\
\hline $\begin{array}{l}\text { Difficulty in studying clinical } \\
\text { procedure }\end{array}$ & Clinical training & 2.94 & 0.981 \\
\hline
\end{tabular}

Notes: DES: Dental Environment Stress, SD = Standard Deviation

Table 5. Correlation between Scores of Dental Environment Stress Categories and Perceived Stress Scale

\begin{tabular}{lcc}
\hline DES Category & $\rho^{*}$ & p-value \\
\hline Self-efficacy & 0.426 & $<0.001$ \\
Lecturers & 0.424 & $<0.001$ \\
Workload & 0.299 & $<0.001$ \\
Clinical training & 0.358 & $<0.001$ \\
Academic performance pressure & 0.429 & $<0.001$ \\
Personal/others & 0.361 & $<0.001$ \\
\hline
\end{tabular}

Notes: DES: Dental Environment Stress, * Spearman's correlation coefficient rho

pact the mental health of educational staff members and dental students due to increased stress and anxiety. ${ }^{3,25}$ The educational process of a profession can be an experience with full psychological stress and pressure, which is a psychological response to various demands in mental, emotional, or physical forms. Stress is a normal response and acts as a protective-adaptive process in the life of an individual, but stress is also capable of causing an individual to experience certain conditions such as anxiety, depression and exhaustion, which have a negative impact on the quality of life. ${ }^{26,27}$

The impact of stress on each individual varies. Sometimes it serves as a source of motivation for students to gain achievement. However, with stressful stimulations and excessive stress, it is possible for them to experience negative impacts in terms of academic performance. This is due to differences in each individual in terms of stress tolerance and motivation. ${ }^{28}$ The consequences of high and intolerable stress levels do not always have a direct impact on student academic performance, but it might have psychological impacts. Therefore, such student feels incapable of continuing his or her education and decides to quit being a dentistry major. ${ }^{29} \mathrm{It}$ has been observed that this is one of the reasons for the decline in the number of dentistry graduates. The low number of dentistry graduates leads to a reduction in number of dentists in an area, resulting in an imbalanced dentists-to-patients ratio. ${ }^{30}$ This imbalanced ratio shows that the population in the area will not receive ideal den-
Table 6. Strongest Positive Correlations between Scores of Dental Environment Stress Items and Perceived Stress Scale

\begin{tabular}{lll}
\hline DES Item & $\rho^{*}$ & p-value \\
\hline Respondent expectation towards faculty of dentistry vs. & & \\
reality & 0.431 & $<0.001$ \\
Lack of confidence to be a successful dentist & 0.424 & $<0.001$ \\
Lack of confidence to be a successful dental student & 0.408 & $<0.001$ \\
Rules and regulations for faculty of dentistry & 0.401 & $<0.001$ \\
Criticism of the work & 0.400 & $<0.001$ \\
\hline
\end{tabular}

Notes: DES: Dental Environment Stress, * Spearman's correlation coefficient rho

tal treatments. 31

Studies in the past three decades showed that dental students experience high-stress levels. ${ }^{14}$ However, this study indicated that the stress level of dental students at the Faculty of Dentistry Trisakti University was categorized into moderate stress level $(20.5 \pm 5.64)$. Furthermore, the mean score comparison between genders indicated that female students have higher perceived stress levels compared to males. This result was in accordance with the studies carried out in Canada, Saudi Arabia and Russia, which stated that female students have higher perceived stress levels compared to males. ${ }^{32,33}$ The collected data ranged from 6 , which was in the 'low-stress level' category or 'low stress,' to 38 , which was in the 'high-stress level' category or 'high perceived stress'.

The stress-causing factor in dental education needs to be identified in order for the objectives of this study to be fulfilled. Therefore, an analysis was performed on six categories of stress-causing factors. The stressor category with the highest mean score was 'academic performance pressure' $(2.86 \pm 0.720)$. This implies that the academic performance pressure put on students, has a had a high potential of increasing students' stress levels due to expectations and goals that are self-imposed, family or society and also, the general thought that academic performance plays a crucial role in shaping one's career. Dental students were faced with the demanding nature of the dental curriculum in order to reach the goal. Therefore, this was one of the many factors contributing to the higher level of stress among them compared to other health-related students. ${ }^{13,34}$

The second dental environmental stressor category with the second highest mean score was the "clinical training' $(2.85 \pm 0.857)$, followed by the 'workload' category $(2.69 \pm 0.834)$. The lowest mean score came from the 'personal/others' category $(1.91 \pm 0.760)$. Although, studies on dental students from various countries showed different causes of stress, majority discovered that the top stress-causing factors originated from the categories of 'academic performance pressure', 'clinical training' 
and 'workload'. Furthermore, the results of this study were consistent with previously published studies. 35,36

In addition correlations between dental environments and stress levels in this study showed positive correlations between all DES factors and perceived stress ( $\mathrm{p}$ value $<0.01$ ). However, a study in Saudi Arabia showed different results, as there were positive correlations between only five DES factors (clinical training, workload, self-efficacy, lecturers and education personnel and academic performance pressure) and perceived stress. ${ }^{14}$

\section{Conclusion}

The stress level of dental students at the Faculty of Dentistry Trisakti University was categorized into moderate stress level. This study showed there is a significant correlation between the dental environment and perceived stress levels among dental students at the Faculty of Dentistry Trisakti University during the COVID-19 pandemic. However, future studies are needed to investigate proper stress management for students. Moreover, the stress-causing factor in dental education needs to be analysed further. This is because, proper stress management techniques are capable of motivating students to measure and overcome stress in order to increase their academic and clinical performance.

\section{Abbreviations \\ DES: Dental Environment Stress; PSS: Perceived Stress Scale; COVID- 19: Coronavirus Disease 2019; SARS-CoV-2: Severe Acute Respiratory Syndrome Coronavirus 2; WHO: World Health Organization.}

\section{Ethics Approval and Consent to Participate}

This study has been ethically reviewed and approved by the Ethics Commission of Faculty of Dentistry Trisakti University with approval number 267/S1/KEPK/FKG/2/2020.

\section{Competing Interest}

The author declares that there are no significant competing financial, professional, or personal interests that might have affected the performance or presentation of the work described in this manuscript.

\section{Availability of Data and Materials}

All data that support the results of this study are with the corresponding author [TEA] and will be made available upon reasonable request.

\section{Authors' Contribution}

TEA and HJ conceptualized and designed this study. HJ carried out data collection, while WS carried out data analysis and interpretation. Furthermore, TEA, ASW, and HJ analyzed the data and edited the manuscript. All authors discussed the study and contributed to the manuscript preparation and review.

\section{Acknowledgment}

The authors express their gratitude to the Faculty of Dentistry, Trisakti
University for their support for this study.

\section{References}

1. Ministry of Health of the Republic of Indonesia. Indonesia health data profile 2018. Jakarta; 2019.

2. Halboub E, Nasser Alhajj M, Mohammed AlKhairat A, Madani Sahaqi A-A, Faeq Ali Quadri M. Perceived stress among undergraduate dental students in relation to gender, clinical training and academic performance. Acta stomatologica Croatica. 2018; 52 (1): 37-45.

3. Machado RA, Bonan PRF, Perez, DESC, Martelli Júnior, Hercílio. COVID-19 pandemic and the impact on dental education: discussing current and future perspectives. Brazilian Oral Research. 2020; 34: e083.

4. Qiu W, Rutherford S, Mao A, Chu C. The pandemic and its impacts. Health, Culture and Society. 2017; 9: 3.

5. Lai CC, Shih TP, Ko WC, Tang HJ, Hsueh PR. Severe acute respiratory syndrome coronavirus 2 (SARS-CoV-2) and coronavirus disease-2019 (COVID-19): the epidemic and the challenges. International Journal of Antimicrobial Agents. 2020; 55 (3): 105924.

6. Abebe EC, Dejenie TA, Shiferaw MY, Malik T. The newly emerged COVID-19 disease: a systemic review. Virology Journal. 2020; 17 (96): $1-8$.

7. Alwan NA, Burgess RA, Ashworth S, Beale R, Bhadelia N, Bogaert D, et al. Scientific consensus on the COVID-19 pandemic: we need to act now. Lancet. 2020.

8. World Health Organization. Coronavirus disease (COVID-19) advice for the public. Geneva: World Health Organization; 2020 [updated 2020 Oct 13].

9. Wyse AE, Stickney EM, Butz D, Beckler A, Close CN. The potential impact of COVID-19 on student learning and how schools can respond. Educational Measurement: Issues and Practice. 2020; 39 (3): 1-5.

10. Deery C. The COVID-19 pandemic: implications for dental education. Evidence-Based Dentistry. 2020; 21: 46-7.

11. Gautam R, Sharma M. 2019-nCoV pandemic: a disruptive and stressful atmosphere for Indian academic fraternity. Brain, Behavior, and Immunity. Brain, Behavior, and Immunity. 2020; 88: 948-9.

12. Aamir IS. Stress level comparison of medical and nonmedical students: a cross sectional study done at various professional colleges in Karachi, Pakistan. Acta Psychopathologica. 2017; 3 (2): 1-6.

13. Murphy RJ, Gray SA, Sterling G, Reeves K, DuCette J. A comparative study of professional student stress. Journal of Dental Education. 2009; 73 (3): 328-37.

14. Al-Sowygh ZH. Academic distress, perceived stress and coping strategies among dental students in Saudi Arabia. Saudi Dental Journal. 2013; 25 (3): 97-105.

15. Elani HW, Allison PJ, Kumar RA, Mancini L, Lambrou A, Bedos C. A systematic review of stress in dental students. Journal of Dental Education. 2014; 78 (2): 226-42.

16. Crego A, Carrillo-Diaz M, Armfield J, Romero M. Stress and academic performance in dental students: the role of coping strategies and examination-related self-efficacy. Journal of Dental Education. 2016; 80 (2): 165-72.

17. Alzahem A, van der Molen H, Alaujan A, Schmidt H, Zamakhshary M. Stress amongst dental students: a systematic review. European Journal 
of Dental Education. 2011; 15 (1): 8-18.

18. Bergmann C, Muth T, Loerbroks A. Medical students' perceptions of stress due to academic studies and its interrelationships with other domains of life: a qualitative study. Medical Education Online. 2019; 24 (1): 1603526.

19. Alhajj MN, Khader Y, Murad AH, Celebic A, Halboub E, Márquez JR, et al. Perceived sources of stress amongst dental students: a multicountry study. European Journal of Dental Education. 2018; 4 (258): 271.

20. Alzahem A, van der Molen, Alaujan, de Boer. Stress management in dental students: a systematic review. Advances in Medical Education and Practice 2014; 167.

21. Alzahem A, Van der Molen H, De Boer B. Effectiveness of a dental students stress management program. Health Professions Education. 2015; 1 (1): 34-42.

22. Das.nh.gov. Perceived stress scale; 2020 [Accessed 21 February 2021].

23. Ersan N, Fisekcioglu E, Dolekoglu S, Oktay I, Ilguy D. Perceived sources and levels of stress, general self-efficacy and coping strategies in clinical dental students. Psychology, Health \& Medicine. 2017; 22 (10): 117585.

24.DeVellis RF. Scale development: theory and applications. Los Angeles: Sage; 2012

25. AlAteeq DA, Aljhani S. Perceived stress among students in virtual classrooms during the COVID-19 outbreak in KSA. Journal of Taibah University Medical Sciences. 2020; 15 (5): 398-403.

26. Basudan S, Binanzan N, Alhassan A. Depression, anxiety and stress in dental students. International Journal of Medical Education. 2017; 8: 179-86.

27. McEwen B, Bowles N, Gray J, Hill M, Hunter R, Karatsoreos I, et al. Mechanisms of stress in the brain. Nature Neuroscience. 2015; 18 (10): 1353-63.
28. Tan SY, Yip A. Hans Selye (1907-1982): founder of the stress theory. Singapore Medical Journal. 2018; 59 (4): 170-1.

29. Bhayat A, Madiba T. The self-perceived sources of stress among dental students at a South African dental school and their methods of coping. Journal of the Dental Association of South Africa. 2017; 71 (1): 1-5.

30. Mahendradhata Y, Trisnantoro L, Listyadewi S, Soewondo P, Marthias T, Harimurti P, et al. The Republic of Indonesia health system review. New Delhi: World Health Organization (on behalf of the Asia Pacific Observatory on Health Systems and Policies). 2017; 7 (1): 1-328.

31. Yadav S, Rawal G. The current status of dental graduates in India. Pan African Medical Journal. 2016; 23: 22.

32. Abu-Ghazaleh SB, Sonbol HN, Rajab LD. A longitudinal study of psychological stress among undergraduate dental students at the University of Jordan. BMC Medical Education. 2016; 16: 90.

33. Myrvold B. Stress among dental students. International Journal of Science and Research. 2018; 7 (7): 891-3.

34. Moridi G, Khaledi S, Valiee S. Clinical training stress-inducing factors from the students' viewpoint: a questionnaire-based study. Nurse Education in Practice. 2014;14 (2): 160-3.

35. Sangiorgio JPM, Araujo PM, Navarro CH, Zen IR, da Costa SC, Ribeiro PHV, et al. Dental environment stress: findings among lusophone dental students. Pesquisa Brasileira em Odontopediatria e Clínica Integrada. 2016.

36. Gordon NA, Rayner CA, Wilson VJ, Crombie K, Shaikh AB, YasinHarnekar S. Perceived stressors of oral hygiene students in the dental environment. African Journal of Health Professions Education. 2016; 8 (1). 